\title{
Erratum to: The Intergovernmental Platform on Biodiversity and Ecosystem Services gets profile
}

\section{Marcus Zisenis}

Published online: 3 March 2015

(C) Springer Science+Business Media Dordrecht 2015

\section{Erratum to: Biodivers Conserv (2015) 24:199-203 DOI 10.1007/s10531-014-0797-0}

The word "International" should be read as "Intergovernmental" in the title as well as in the first sentence of the abstract and introduction. The updated version is provided below.

Abstract "This paper contributes to the discussion of implementing the newly established Intergovernmental Platform...."

Introduction "The Intergovernmental Platform on Biodiversity and Ecosystem...."

The online version of the original article can be found under doi:10.1007/s10531-014-0797-0.

M. Zisenis $(\bowtie)$

Eisenacher Straße 54, 10823 Berlin, Germany

e-mail: marcus.zisenis@alumni.tu-berlin.de 